\title{
Deploying actor-network theory to analyse telemedicine implementation in Ghana
}

\author{
Eben Afarikumah ${ }^{1,3}$, S. Yunkap Kwankam ${ }^{2,4}$ \\ ${ }^{1}$ Candidate, Open University of Malaysia/Accra Institute of Technology, Accra \\ ${ }^{2}$ Chief Executive Officer, Global eHealth Consultants, Geneva, Switzerland \\ ${ }^{3}$ Council for Scientific and Industrial Research-Ghana \\ ${ }^{4}$ Executive Director, International Society for Telemedicine and eHealth (ISfTeH), Geneva, Switzerland
}

\section{Email address:}

afari.telemedicine@yahoo.com(E. Afarikumah)

\section{To cite this article:}

Eben Afarikumah, S. Yunkap Kwankam. Deploying Actor -Network Theory to Analyse Telemedicine Implementation in Ghana. Science Journal of Public Health. Vol. 1, No. 2, 2013, pp. 69-76. doi: 10.11648/j.sjph.20130102.15

\begin{abstract}
This paper presents the pan African eNetwork for Telemedicine and Tele-education programme being run at the Komfo Anokye Teaching Hospital in Ghana. The study sought to understand eHealth implementation in low resource settings through the lens of actor-network theory. This theory is based on the sociology of translations, and was employed as a framework for exploring the pan African Telemedicine programme. Data collection was done between October, 2011 and June 2012, through triangulation of qualitative methods: interviews, participant observation, and document analysis. A total of 30 human and non-human actors' were identified and semi-structured face-to-face interviews conducted with the human actors. Translation, the mechanism of progressive temporal social orders, or the transformation from one order to another through changes in the alignment of interest in a heterogeneous network (Sarker, Sarker and Sidorova, 2006), has not been effective and thus implementation of the eNetwork has not been successful. Future studies should focus on staff acceptance of the eNetwork.
\end{abstract}

Keywords: Ghana, Telemedicine, Health, Actor Network Theory

\section{Introduction}

Ghana is experiencing high attrition of doctors (Sodzi-Tettey, 2007:146), with a large number of doctors reluctant to accept postings to rural and remote areas. Telemedicine (TM) could help address these challenges (Houston and Houston 2000; Mbarika 2004), as it can support more equitable access to medical services in cities as well as remote areas in Ghana.

Reliable information and effective communication are crucial elements in health institutions, disease monitoring and prevention, public health systems, and health care generally. Information and communication technology (ICT), therefore, can be a vital tool in combating disease, promoting individual health and making health systems more effective and efficient.

It can be particularly powerful in monitoring the outbreak and spread of disease, disseminating health information (including information about health-promoting and disease-preventing individual behavior), and providing training, information and long-distance support to health care practitioners. However, a challenge for developing countries is to ensure that ICT is effectively mobilized to improve health outcomes and combat disease among the poorest and most remote populations. This is an area where the potential for effective use of the full range of ICTs (including radio and television) is particularly great.

Improving the health of individuals and communities, and strengthening health systems, disease detection and prevention are crucial to development and poverty reduction. ICT has the potential to impact almost every aspect of the health sector. In public health, information management and communication processes are pivotal, and are facilitated or limited by available ICT1. In addition, beyond the formal health sector, the ability of impoverished communities to access services and engage with and demand a health sector that responds to their priorities and needs, is importantly influenced by the availability of information and communication processes, mediated by ICT. ICT could impact greatly on referrals, emergency and

\footnotetext{
${ }^{1}$ http://www.infodev.org/en/TopicBackground.6.html
} 
disaster management and support blood banking, as "by the press of on a knob, personnel at the primary level can alert those at higher levels to mobilize an ambulance to save a life" (Eleeza, 2005). From patient record management, through video conferencing and health networking, various ICT tools such as computers, cameras and the Internet have been of greater benefits to the health workers in enhancing quality healthcare delivery to people across the world, especially those from developing countries. Currently the multiple folder system operating at some health facilities made it difficult for health workers to track the records of patients on reactions to drugs and others, since they would have different folders for every department visited.

Shekelle et al (2006) believe that use of ICT willlead to improvements in healthcare quality (e.g through better communications) and efficiency (e.g. through reduced duplication of investigations). (Davis et al. (2010)). Australia, New Zealand, and the UK have been at the forefront of attempts to embed ICT into routine healthcare. However, in the case of the UK, the national Audit office (2006) reported that despite political commitment and substantial investment, there has been significant variability in the success of different eHealth implementations across the National Health Service.

\subsection{Significance and Value of Developing the Telemedicine Network}

Inspired by advances in the provision of healthcare and medical education through the use of Information and Communication Technology, noting India's long history of assisting Africa in capacity building programmes and recognizing that Africa-India cooperation can play a major role in harnessing the benefits of globalisation for mutual advantage, the former President of India Dr. A. P. J. Abdul Kalam, during the inaugural session of the Pan-African Parliament held in Johannesburg on 16th September 2004, proposed in his address to connect all the 53 nations of the African Union by a satellite and fiber optic network that would provide effective communication for Tele-education, Tele-medicine, Internet, Videoconferencing and VoIP services and also support e-Governance, e-Commerce, infotainment, resource mapping, meteorological services etc. (Pan-African eNetwork project report ${ }^{2}$ )

Key Benefits of the eNetwork were to include the use of electronic ICT to provide and support health care irrespective of the distance between the doctor and the patient.

\subsection{Actor Network Theory (ANT)}

The basic idea of ANT is that, in order to achieve a goal, a network of faithful alliances needs to be created to carry the network builders' intentions and materialise their goals.

The theory holds a distinctive view of society as a network of humans and non-humans that interact and

\footnotetext{
${ }^{2}$ http://125.16.61.40/V-Learn/PortalMgmt/aboutdep.jsp?aboutus=1
}

cooperate to pursue a certain goal. It therefore maintains that any network building would involve the recruitment of human and non-humans. Network building takes place through translations. Translation is the mechanism by which the network builder recruits actors and ensures their faithful alliance. It was first coined and used by Michel Serres (Callon and Latour 1981; Seres 1974) and published by Callon (1986).

"the actor-network theory describes the dynamics of society in terms totally different from those usually used by sociologists." (Callon (1987 p.97))

A socio-philosophical approach of the actor-network theory "...rejects any sundering of human and nonhuman, social and technical elements." (Hassard, Law and Lee 1999 p.338).

Callon (1986) described that the sociology of translation is composed of four moments, namely problematization, interessement, enrolment and mobilisation.

Problematization is the first moment of translation, which relates to the process of a focal actor striving to become indispensable to the other actors by defining the problem and motivating them into the network, and suggesting that the problem would be resolved if the actors negotiated the "obligatory passage point (OPP)". Problematization describes a product of alliances, or associations between actors by identifying what they want (Callon 1986). OPP refers to a process in which a focal actor convinces all other actors to accept the proposal of a network. OPP also refers to a process in which a focal actor shows an interest in all the actors who accept the proposed network (Callon 1986).

Interessement is the second moment of translation, which relates to a series of processes where a focal actor attempts to lock other actors into a position that has been offered to them in the network. Interessement also means the group of actions by which the focal actor aims to impose and stabilise the other actors' identity. These actions are defined through the problematization process. Different devices for different actors are used in these actions. For example, in the scallop case, some devices of the interessement process had a favourable balance of power: the fishermen's device was the towlines in St. Brieuc Bay and their scientific colleagues used devices such as texts and conversation, which attracted the actors concerned to follow the project (Callon 1986). If the interessement succeeded, then enrolment could take place.

Enrolment is the third moment of translation, which refers to a set of strategies in which a focal actor attempts to define and inter-relate the various roles that allow other actors to enrol. The process of enrolment involves "group multilateral negotiations, trials of strength and tricks that accompany the interessements and enable them to succeed" (Callon 1986 p.211). When the negotiation between actors has been achieved, the inscription appears. The inscription is a process of artefact creation that ensures the protection of some interests (Sarker, Sarker and Sidorova 2006). In brief, an enrolment relates to the other actors' acceptance 
of the interests defined by a focal actor through the process of bargaining and making concessions (Madon, Sahay and Sahay 2004; Sarker, Sarker and Sidorova 2006).

Mobilisation is the final moment of translation, which relates to a set of manners utilised by a focal actor to ensure that all actors have legitimate speakers to represent them in groups, and avoid betrayal in various collectives from the latter (Callon 1986; Madon, Sahay and Sahay 2004). Speakers or representatives are actors who speak or deputise for other actors (Walsham 1997).

\subsection{Central Concepts of ANT}

Table 10. Key concepts of Actor-Network Theory

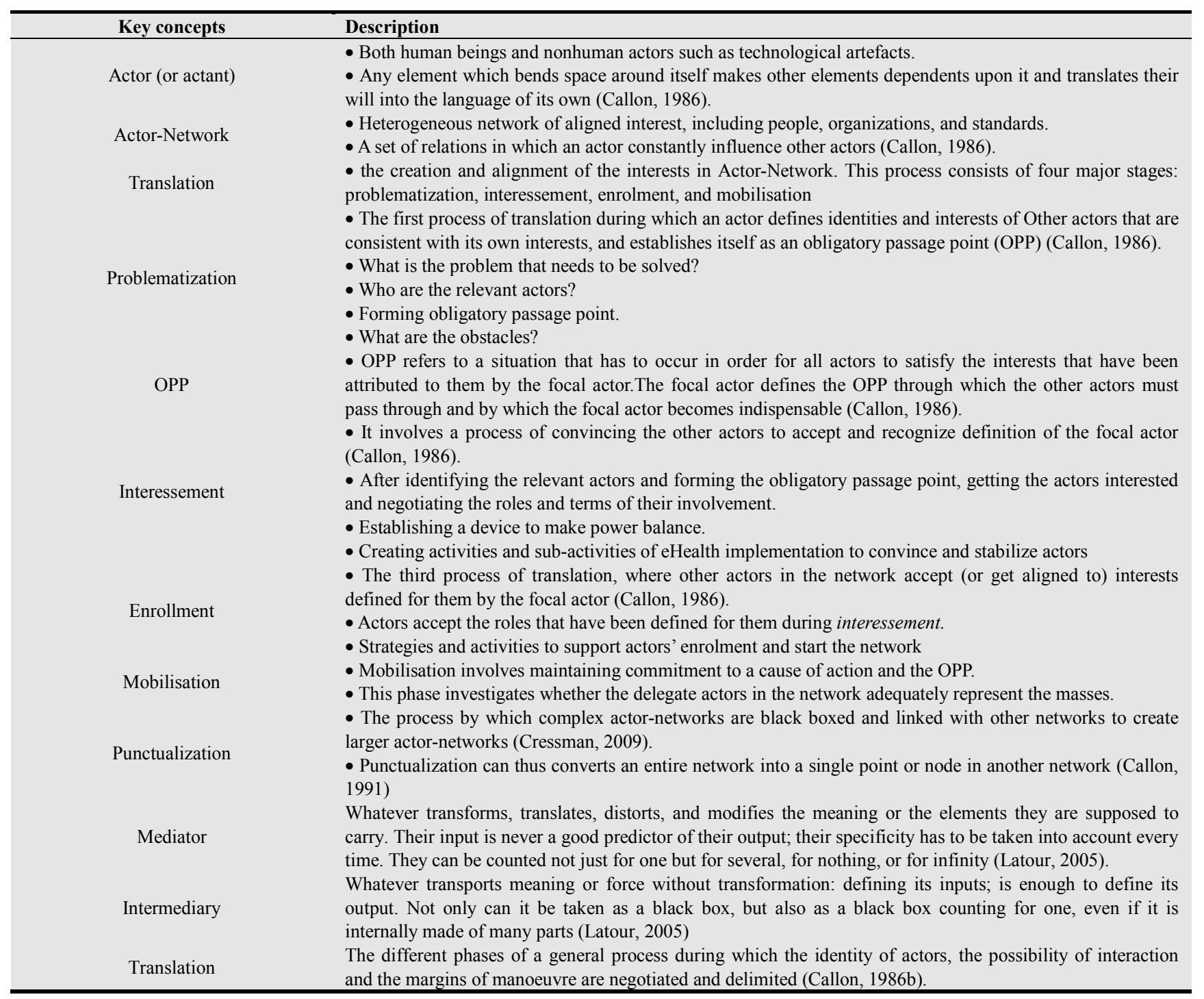

\section{Research Methodology}

A case study methodology was adopted and carried out using semi-structured interviews with implementers for data collection. The actor-network is a unit of analysis in this study. Approval for the study was obtained from the
ANT's vast potential for explaining the complex social interactions associated with information technologies has been recognized by previous research (Walsham, 1997; Hanseth, Aanestad et al., 2004). ANT approach has been widely accepted to interpret surrounding process of technology implementation projects (Hanseth and Monteiro, 1997; Walsham and Sahay, 1999; Mitev, 2000). Although there are a lot of key concepts in actor-network theory (Walsham, 1997), only two key concepts are described elaborately, as these two are equally necessary for analyzing the eHealth project. 
semi-structured questionnaire, informal discussions, telephone conversations and in some cases video conferences with participants (Table 1). Data collection was from January 2011 to July 2012. The data collected were triangulated to different data sources, so as to build a coherent justification for common themes (Creswell, 2003). The project site was analyzed in parts and whole using Creswell (2007) within-case, cross-case and holistic-case analysis template. Table 2 provides further details on interviews conducted during the fieldwork.

Table 1. Sources and Techniques used for Data Gathering

\begin{tabular}{|c|c|}
\hline e & tion \\
\hline $\begin{array}{l}\text { Semi-Structured } \\
\text { Interviews }\end{array}$ & $\begin{array}{l}\text { Face-to-Face interviews were conducted with Nodal Officers, eHealth project initiators, Telemedicine managers and } \\
\text { Technicians, Chief Executive Officers and Healthcare Professionals who play important role in the eHealth Projects as well as } \\
\text { external software developers and governmental partners. The interviews were based on semi-structured interview guide flexibly } \\
\text { designed to account for emergent views, concepts and themes from field participants and settings. Each formal interview lasted } \\
\text { between } 10 \text { and } 45 \text { minutes, was tape-recorded following participants' consent. Table } 7-3 \text { provides more detail on the } \\
\text { interviews. }\end{array}$ \\
\hline $\begin{array}{c}\text { Informal } \\
\text { Conversation }\end{array}$ & $\begin{array}{l}\text { eries of informal conversations were undertaken with Nodal Officers, eHealth project initiators, Telemedicine managers and } \\
\text { hnicians, Chief Executive Officers and Healthcare Professionals who play important role in the eHealth Projects as well as } \\
\text { ernal software developers and governmental partners. Such conversations were not tape-recorded but immediately written-up } \\
\text { er each session. I also used largely informal talks to get clarity of issues that were not clear to me. }\end{array}$ \\
\hline Document Analysis & $\begin{array}{l}\text { The researcher gathered data internally from case organisations and their websites and externally from general internet and } \\
\text { newspaper search. } \\
\text { Internal documents included business plans, documentation on systems on systems planning, design and development; } \\
\text { brochures, advertising materials and invoices, correspondence including letters and emails between management and external } \\
\text { parties such as software developers and consultants, clients, contract documents with external entities. } \\
\text { External documents from general internet search and newspaper sources included articles, commentaries, and reviews written } \\
\text { about the firms, their services and technologies. The external sources also provided rich background data about the broader } \\
\text { socio-technical eHealth solutions environment in both Ghana and India within which eHealth emerged. }\end{array}$ \\
\hline $\begin{array}{c}\text { Telephone } \\
\text { Conversation }\end{array}$ & $\begin{array}{l}\text { eries of telephone conversations were undertaken with some Nodal Officers, eHealth project initiators, Telemedicine } \\
\text { nagers and Technicians, and Healthcare Professionals who played important role in the eHealth Projects as well as external } \\
\text { ware developers and governmental partners. Such conversations were not tape-recorded but immediately written-up after } \\
\text { h session. }\end{array}$ \\
\hline Observation & $\begin{array}{l}\text { Silverman (2005) identified observation as being fundamental to understanding another culture. Through participant } \\
\text { observation, the researcher observed the participants, how they interacted, their routines, rituals, temporal elements or critical } \\
\text { incidents, interpretations and social organization. The researcher participated in eHealth and telemedicine sessions to } \\
\text { understand the process. } \\
\text { This was informed by the suggestion of Denzin (1989) as to what to observe in a field study } \\
\text { In addition, the researcher observed and captured pictures and video data about the nature of available geographic specific } \\
\text { infrastructure. }\end{array}$ \\
\hline
\end{tabular}

Table 2. Interviews conducted

\begin{tabular}{ccccc}
\hline Project Name & Location & Number of Interviews & $\begin{array}{c}\text { Interview Duration } \\
\text { (Min, Max) }\end{array}$ & Interaction Type \\
\hline eNetwork & Kumasi, Ghana & 20 & $(15,35)$ & Face-to-Face (20) \\
\hline
\end{tabular}

\subsection{Case Description}

The Pan Africa eNetwork project, estimated to cost billion of dollars was a promise made by the Indian President, Dr. A. P. J. Abdul Kalam at the African Union (AU) conference in Johannesburg on September 16, 2004, to provide instant connectivity between African leaders (VVIP network) together with tele-medicine and tele-education

The e-network project covered 53 nations of the AU by satellite and fibre optic network to promote tele-medicine, tele-education and VVIP connectivity. The project aims to put the AU countries on the path to achieving the Millennium Development Goals by contributing significantly to socio-economic development and productivity in the beneficiary countries. The e-education and e-medicine aspects of the project in particular were to provide the opportunity to extend essential ICT infrastructure to certain rural communities and under-served areas and bring excellent applications in health and education to their doorstep.

\section{Sociology of Translations}

This section describes and analyses the project through the lens of the actor- network theory. Sociology of translation is used as a crucial framework to investigate and explain the eNetwork Implementation.

\subsection{Problematisation}

In the problematisation phase, the originator becomes indispensable by presenting a solution to a problem. In the case of the eNetwork, it was meant to provide connectivity between African leaders (VVIP network) together with 
tele-medicine and tele-education. The problematisation was expressed as follows:

"We believe that the successful implementation of the projects will go a long way to minimize the disparities in development between our urban and rural communities and hopefully, contribute to the early realization of our MDGs".

The solution to this problem however demanded many actors. The Indian Government was to provide the experts, hardware and software and the Government of Ghana was responsible for other aspects. Ghana's Ministry of Communications worked closely in collaboration with the Ministry of Education and Ministry of Health to identify appropriate interlocutors for the tele-education and tele-medicine respectively, as designated hubs to interact with their Indian counterparts, as the main service location would be in India. Experts from the three ministries were in touch with their counterparts in India to share knowledge and experience on how to develop appropriate content for the efficient use of the facility, the commencement of which was slated for January 2007 and Komfo Anokye Teaching Hospital was identified to implement the telemedicine component of the eNetwork.

It was gathered from interviews that an MOU between the A.U and the Indian government to provide tele-education to all 53 African countries was signed. The Indian technicians and engineers then came down to set-up the project with the main aim to provide tele-education from specialty hospitals and institutions from India to Ghanaians.

\subsection{Interesement}

The beginning of the eNetwrok implementation process at Komfo Anokye was marked by initial consultations between the stakeholders. These consultations were done through several meetings.

It was gathered that no doctor was involved during implementation process, except the medical director but then his involvement was on a know-how issues basis. On the importance of the eNetwork to the Hospital, I was told that the former Chief Executive was very happy with it and even had advanced ideas as regard to its usage because by then Komfo Anokye had a program for Continuing Medical Education (CME) that they continued to give free medical education, they organize conferences, workshops so they realize that this could be an added advantage to them so they didn't encounter any opposition.

All the responded agree that in the first year of the project, the beginning was fantastic; when you come you can get not less than 15 people per session and that most of their problem were addressed however after sometime the interest went down. In this case the eNetwork was seen as an obligatory passage point.

\subsection{Enrolment}

Several actors were enrolled in the eNetwork implementation process. They included a national coordinator from the Ministry of Communication and a local coordinator at KATH who is the head of Information Technology Department. The local coordinator was assisted by a team made up of a technician and his assistant. The Chief Executive Officer, who himself was much involved in providing strategic direction for the project, visited India on this project. He emphasized that "The Indians brought all their other teams: the software engineer, the network engineer, and the project engineer. The local team assisted them during installation and set-up process and after this, the trained us".

In the bid of the IT staff to get all staff involved after the set up was completed, all the directors, staff, the general public and the press were invited to the centre for the inauguration and demonstration of the system to create awareness. After this event, status reports on tele-medicine were presented to management. Thus at the management level everybody knew there was a centre and what happened there. However, among the other staff, only a few of them knew. An email address was created so that monthly schedules received from India could be sent to all staff.

A doctor corroborated this assertion as follows "With me I started to do when I was in Komfo Anokye that was three years ago and I didn't have a base so I used that time to go and listen but for the last two years I have not been there. Firstly I haven't been on their radar - they used to send me emails about the program and I haven't seen any recently, so if you ask me today (my response) is just simple I wouldn't be able to tell you. But for the first year, that was in 2009, I knew every week that I'd go and visit. Now I don't know if this is there anymore and if it was I would at least know about it and maybe attend once a month or so".

For some people, it appears they have given up because the eMails have stopped coming on monthly basis. Some challenges identified and recommendations provided for a successful implementation and sustainability of eNetwork by respondents include (a) "Time. It is normally around 11 to 12 and that was like the middle of the day and for us if you are in our primary care, we are given slots so you would have to be in a clinic from 8 am to $2 \mathrm{pm}$. So you can't just go and listen and then stay there for one hour. It's not the best for Komfo Anokye so I used to attend when I didn't have clinic but sometimes you really want to listen and you have a clinic so you are torn between the two. The timing was the problem. So, my recommendations is that if it was early in the morning or in the middle that would maybe help a larger number of people to attend. In addition, the venue was OK because we were very few in number, but if the preview screen was bigger then we wouldn't fall on each just to listen. I was very impressed how Komfo Anokye was able to put up such a system. I was ashamed that we were not more and I have even forgotten about it since I stopped."

(b) It should be recognised and accredited as Continuing Professional Development (CPD) and that would hopefully 
attract more people so that they would get something out of it, for them to be motivated.

(c) I suggest that they keep encouraging us, the mails should be coming every month with different colours.

(d) To convince other doctors to participate in this system regularly, we have to talk to them on a one-on-one basis, and then if they see that you are up to date because of those programs, they would also respond

(e) We should also open it to other doctors besides doctors in Komfo Anokye because for all you know these other doctors maybe more interested in such programs.

\subsection{Mobilisation}

Once the needs of the different actors are met, it is possible for some actors to speak on behalf of the focal actor (Latour, 2005). After years of the implementation, Staff members are still complaining about the system. It was gathered that the managers of the various directorates attended. They knew about the eNetwork but they do not inform their staff or bring them on board. It can be concluded that they were not successful in mobilising the staff to patronise the eNetwork. In order to mobilise staff, it was suggested the program should be posted on notice boards within the hospital and in quarters where our staff stays; or send adverts to other hospitals.

A respondent indicated that efforts were putt in place to bring the Doctors on board since they are suppose to be the main users included lobbying through management and in this direction, a memo was sent to the medical director on the issue with a response awaited. It was suggested that "In addition, management could allow the Ghana College of Surgeons and Physicians to come in and give accreditation to it so that if a doctor will be compelled to attend." Awareness must be created for all stakeholders to embrace the eHealth solution.

\section{Discussion}

With the exception of five (5) respondents who were not available to be interviewed despite confirmed appointments with them, data collection on site was very successful. The Actor-network theory tries to explain how material-semiotic networks come together to act as a whole; the clusters of actors involved in creating meaning are both material and semiotic. The researchers used it to look at explicit strategies for relating different elements of the pan African eNetwork together into a network so that they form an apparently coherent whole. According to (Latour, 2005), these networks are potentially transient, existing in a constant making and re-making this means that relations need to be repeatedly "performed" or the network will dissolve. It was also observed that some of the respondents greatly appreciated the work done by the Indian Government and are aware of the value of the eNetwork to healthcare delivery in Ghana, however, time difference between Ghana and India, workloads constraints, non availability of a telemedicine champion, are some of the key reasons why they are not reaping its full benefits. It was observed that, although the project has both education and health components, the ministries of health and education do not have a representative. Although staff have been brought on board, they do not have a champion for the project. Most of the key people do not have time for the project. The staff perceives the project an as optional system. Technically, the staff consider the system as an IT device and thus, are focused more on maintaining the mainstream IT equipment. They have equally not been exposed to functional telemedicine system. From an Actor network theory perspective, we can clearly conclude that the network is dissolving or failing.

Looking beyond KATH to the pan African eNetwork as a whole, there were at least three non-human actors which played key roles in the eNetwork. Firstly, the Architecture of the eNetwork was a major contributor to the lack of success. While the project aimed at providing Internet connectivity to African institutions, the architecture limited these institutions to connecting to Indian centers only. It was not an interconnected network of African institutions but a system of African institutions all connected to Indian centers, but not otherwise linked to one another. It was thus, at best, a star-connected (hub and spoke) network, with nodes connecting with other nodes through the hub. Experience showed that sharing of experiences and knowledge among the nodes was very limited. Thus, Nigeria and Ghana, which conceivable have a lot in common in terms of medical education challenges, could not share experiences directly through the eNetwork. The architecture thus constrained the network to focusing on those medical education challenges where the solutions could be found in the Indian centers. This severely limited the power of the pan Africa eNetwork. The power of a fully interconnected network grows as the square of the number of its nodes (Metcalfe's Law ${ }^{3}$ ) precisely because of the direct links among the nodes.

A second contributing actor, of an organizational nature, was the scheduling of the courses. Each Indian center delivered a given course to all Medical schools in the eNetwork at the same time. Optimal scheduling was a problem because of time differences, with Medical schools spanning several zones from Dakar in Senegal (UTC) to Port Louis in Mauritius (UTC+4). Individual institutional priorities added further complexity to the scheduling challenge.

Finally, language played an important role in limiting the attainment of the goals of the network. Course material was only available in English, whereas the language of instruction in some of the Medical schools in the eNetwork is either French or Portuguese.

\section{Conclusion}

The Indian government initiated the project for African Union. The government of Ghana's Ministry of

\footnotetext{
${ }^{3}$ http://www.businessdictionary.com/definition/Metcalfe-s-Law.html
} 
Communications took over the project. They liaised with TCIL and KATH to implement the project. A series of meetings were held to get the project started. For the system to function, the actors must create awareness about it among all staff. It can be confirmed from the interviews that staff do not even know that the eNetwork exists. It is recommended that position, such as an Operations Manager/Project Manager, and an Outreach Coordinator, be created. They should be responsible for the day-to-day operations of the network, supervision of technical staff and vendor relations. They would also need to work with customers to implement both clinical and education programs. Future studies should focus on staff and patients' acceptance of the eNetwork and how to integrate Telemedicine services into the health care delivery systems.

\section{Ethical Review}

Ethical approval for the study was granted by the School of Medical Sciences/Komfo Anokye Teaching Hospital, Committee on Human Research Publication and Ethics, and the Council for Scientific and Industrial Research's Institutional Renewal Board.

\section{Acknowledgements}

The authors would like to thank the Indian government for the award of the prestigious CV Raman International Fellowship for African Researchers, 2011 edition which enabled the lead author to spend 3 months at School of Telemedicine and Biomedical Informatics ${ }^{4}$, Sanjay Gandhi Postgraduate Institute of Medical Sciences, Lucknow, India and Telemedicine Centres of excellence and collect data on the Pan African eNetwork under host Scientist Prof. S.K Mishra, Head, Dept. of Surgery \& Nodal Officer, Telemedicine.SGPGIMS, Lucknow, India.

\section{References}

[1] ACCORD, (2009). HEALTH CARE IN GHANA. March 2009. Accessed on 04/23/2013 from http://www.ecoi.net/file_upload/90_1236873017_accord-h ealth-care-in-ghana-20090312.pdf

[2] Callon, M. (1991), "Techno-Economic Networks \& Irreversibility in sociology of Monsters: Essays on Power, Technology and Domination, (Law, J. Ed.) Routledge, London, pp. 132-161

[3] Callon, M. (1986), "The sociology of an actor-network: The case of the electric vehicle". (in J. L. Callon and A. R. Houndmills Ed., Mapping the dynamics of science and technology: Sociology of science in the real world), London: Macmillan.
[4] Callon, M. (1986), "Some elements of a sociology of translation: Domestication of the scallops and the fishermen of St. Brieuc Bay".(in J. Law Ed., Power, action and belief: A new sociology of knowledge?), London, Boston, and Henley: Routledge \& Kegan Paul, pp. 196-233.

[5] Callon, M 1987, 'Society in the making: The study of technology as a tool for sociological analysis', in WE Bijeker, $T$ Hughes \& $T$ Pinch (eds), The social construction of technology systems: New Directions in the Sociology and history of Technology, The MIT Press, Cambridge, Massachusetts and London, England, pp. 83-103.

[6] Callon, M. and B. Latour (1981), "Unscrewing the big leviathan: How actors macro-structure reality and how sociologists help them to do so".(in K. D. Knorr- Cetina and A. V. C. (Ed., Advances in Social Theory and Methodology: Towards an Integration of Micro and Macro-Sociologies), London: Routledge and Kegan Paul, pp. 277-303.

[7] Creswell, J.W. (2003). Research Design: Qualitative, Quantitative and Mixed Methods Approaches. 2nd ed. London: Sage Publications, Inc.

[8] Cressman, D. (2009). A brief overview of Actor-network theory: Punctualization, Heterogeneous Engineering \& Translation, ACT Lab/Center for Policy Research on Science \& Technology (CPROST) School of Communication, Simon Fraser University, Canada.

[9] Denzin, N.K. (1989). The research acts (3 ${ }^{\text {rd }}$ ed.). Englewood Cliffs, NJ: Prentice hall

[10] Eleeza, B. J (2005). ICT to facilitate health care delivery -Doctor.

http://www.ghanaweb.com/GhanaHomePage/health/artikel .php?ID $=95227$ assessed on 15/02/2013

[11] Hanseth, O., M. Aanestad, et al. (2004), "Guest editors' introduction: Actor network

[12] Hanseth, O. and E. Monteiro (1997), "Inscribing behavior in information infrastructure standards." Accounting, Management \& Information Technology, Vol: 7, No:4, pp.183-211.

[13] Hassard, J., Law, J., \& Lee, N. (1999). "Preface." Organization: Special Issue on Actor-Network Theory. 6 (3), pp. 387-390.

[14] Houston $\mathrm{T}$ and Houston $\mathrm{J}$ (2000). Is telemedicine a practical reality? Association for Computing Machinery. Communications of the ACM, 43(6), 91-95.

[15] Hjelm NM. (2005). Benefits and drawbacks of telemedicine. J Telemed Telecare. 2005; 11(2):60-70.

[16] IRIN - Integrated Regional Information Network: Ghana: Race Against Time To Cut Maternal Mortality, 5 August 2008

http://www.irinnews.org/report.aspx?ReportID=79645 (accessed 04/23/2013) In ACCORD, (2009). HEALTH CARE IN GHANA. March 2009

[17] Latour, B (2005). Reassembling the Social: An Introduction to Actor-Netowrk-Theory (Oxford: Oxford University Press) 
[18] Madon, S., Sahay, S., and Sahay, J. (2004) Implementing property tax reforms in Bangalore: An actor-network perspective. Information and Organization 14: 269-295.

[19] Mbarika, Victor Wacham A. (2004): Is telemedicine the panacea for Sub-Saharan Africa's medical nightmare? Commun. ACM 47(7): 21-24

[20] Murdoch J, 1997, "Inhuman/nonhuman/human: actor-network theory and the prospects for a nondualistic and symmetrical perspective on nature and society" Environment and Planning D: Society and Space 15(6) $731-756$

[21] Monteiro, E. \& Hanseth, O. (1996) Social shaping of information infrastructure: on being specific about the technology. In: Information Technology and Changes in Organisational Work, Orlikowski, W.,Walsham, G., Jones, M.R. \& Degross, J (Eds.), pp.325-343. Chapman \& Hall.

[22] Sarker, S, Sarker, S and Sidorova, A (2006). Understanding Business Process Change failure: An Actor-Network Perspective. Journal of Management Information Systems, Vol. 23, no. 1, pp.51-86

[23] Sodzi-Tettey, S (2007): GMA@50: Ghana $\square$ s health. Ghana Medical Journal. September 2007 Volume 41, Number 3

[24] Shekelle PG, Morton SC, Keeler EB. Costs and benefits of health information technology. Evid Rep Technol Assess (Full Rep) 2006:1e71.
[25] Mitev, N. (2000), Toward social constructivist understandings of IS success and failure: introducing a new computerized reservation system, International Conference on Information Systems archive. Queensland, Australia

[26] Tan, J., M. Kifle, V. Mbarika, and C. Okoli (2005). E-medicine diffusion: E-medicine in Developed and Developing Countries. Chapter 8 in E-health Paradigm Shift: Perspectives, Domains and Challenges.

[27] Van den Boom, G.J.M; Nsowah-Nuamah, N.N.N.; Overbosch, G.B: Healthcare Provision and Self-medication in Ghana, October 2004 (accessed via Web Archive) http://web.archive.org/web/20070625163825/http://www.s aga.cornell.edu/images/vandenboom.pdf (accessed 04/23/2013) In ACCORD, (2009). HEALTH CARE IN GHANA. March 2009

[28] Wootton R, Hebert MA. What constitutes success in telecare? Journal of Telemedicine and Telecare 2001;7 (suppl. 2):3-7

[29] Walsham, G. \& Sahay, S. (1999), "GIS for District-Level Administration in India: Problems and Opportunities", MIS Quarterly, 23(1), 39 - 66.

[30] Walsham, G. (1997), "Actor-network theory and IS research: current status and future prospects," IN Lee, A., Liebenau, J. \& Degross, J. (Eds.) Information systems and qualitative research. London, Chapman and Hall. 